Sanskrit Ooetics

as a $S_{\text {tudy }}$

of Aesthetic 



\title{
Panskrit Poetics
}

\author{
as $a$ \\ Stully \\ of Stesthedic \\ B Y S . K . D E
}

WITH NOTES BY EDWIN GEROW

UNIVERSITY OF CALIFORNIA PRESS

Berkeley and Los Angeles

1963 


\title{
University of California Press \\ Berkeley and Los Angeles, California
}

\author{
Cambridge University Press \\ London, England
}

(C) 1963 by The Regents of the University of California Library of Congress Catalog Card Number 63-15964

Designed by Theo Jung

Printed in the United States of America 


\section{The Rabindranath Tagore \\ Memorial Lectureship}

was established in 1961, the centenary of the Nobel Prize winning poet of India, to honor the life and work of a man whose contributions to arts and letters were of universal significance, although expressed in terms reflecting his own culture. The annual lectures are devoted to major themes relating to Indian civilization.

The Lectureship is administered by a committee of the Association for Asian Studies, and is composed of members drawn from the sponsoring universities: Columbia University, Harvard University, University of California, Berkeley, University of Chicago, University of Michigan, University of Pennsylvania, and University of Wisconsin.

$$
1961-1962
$$

PATRONS

Mr. and Mrs. Harvey Breit

The Asia Foundation

The Association for Asian Studies, Inc.

The University of Chicago, Committee on Southern Asian Studies

Host University. The University of Chicago

Chairman. Milton Singer

Program Chairman. Edward C. Dimock, Jr. 
